Bruce Seaman, “¿Qué está en juego al optar entre distintas formas de apoyo para el sector cultural?" Estudios Públicos 146 (2017).

\title{
INSTRUMENTOS DE APOYO A LA GESTIÓN DE ENTIDADES CULTURALES COMPLEJAS
}

\author{
Justo Pastor Mellado
}

Crítico de arte

\begin{abstract}
Resumen: Para el autor, la conferencia de Seaman es una buena excusa para pensar en el caso chileno y en cómo adaptar las instituciones que tenemos a la realidad comunal, fuera de Santiago. Para ello, usa como ejemplos sus experiencias con la biblioteca pública de la municipalidad de El Carmen y el Museo de Arte de Rio (MAR).

PAlabras Clave: museos, bibliotecas municipales, política cultural, centro cultural, comunidad.
\end{abstract}

\section{INSTRUMENTS OF SUPPORT FOR THE WORK OF COMPLEX CULTURAL ORGANIZATIONS}

ABSTRACT: The author is prompted by Seaman's lecture to reflect on the Chilean context and on how the country's institutions might best adapt to the situation in the communes, outside Santiago. His examples are drawn from his experience with the public library in the municipality of El Carmen and the Rio Art Museum.

KEYwORDs: museums, municipal libraries, culture policy, arts centres, community.

Justo Pastor Mellado. Crítico de arte y curador independiente. Entre los años 2010 y 2014 dirigió el Parque Cultural de Valparaíso. Email: justomellado@yahoo.com.

* Versión revisada del comentario hecho a la conferencia de Bruce Seaman expuesta el 24 de noviembre de 2016 en el CEP y publicada en este número de Estudios Públicos. 
gradezco la invitación a comentar el trabajo de Bruce Seaman.
Su lectura me ha puesto de manera directa frente a problemas que tuve que enfrentar siendo asesor en el gabinete del ministro de Cultura Luciano Cruz-Coke durante el año 2010 y director del Parque Cultural de Valparaíso entre 2011 y 2014.

La lectura del artículo de Bruce Seaman permite el acceso a insumos que pueden ser de extrema utilidad a la hora de tomar decisiones en el campo de la gestión de dispositivos culturales complejos. Su punto de partida implica el reconocimiento de la necesidad de que tanto el arte como la cultura puedan ser efectivamente apoyados por el Estado; ya sea mediante iniciativas fiscales directas en la forma de subsidios para artistas e instituciones, o a través de programas indirectos en la forma de franquicias tributarias a donantes privados y tratamientos impositivos diferenciados.

Sin embargo, los instrumentos de apoyo se deben a una política y no pueden ser considerados por sí mismos como una política. La experiencia que he adquirido en proyectos de gestión de arte contemporáneo en particular, como de gestión cultural en general, me ha conducido a desconfiar de la "gestión por la gestión".

Agradezco la invitación a comentar el trabajo de Bruce Seaman, porque me sitúa en un lugar de reflexión que no me resulta ni habitual ni cómodo. Sin embargo, es en estas zonas de incomodidad analítica que avanza el conocimiento, sobre todo en lo relativo a los instrumentos de apoyo referidos. Le agradezco a Juan José Price ${ }^{1}$ la diligencia y cortesía por haber discutido previamente conmigo el trabajo de Bruce Seaman, dado que mi anglofobia es directamente proporcional a mi francofilia. Más allá de la broma, confieso el uso mayoritario de bibliografía francesa acerca del tema, lo cual es un punto a considerar en nuestro debate. Lo que busco, en general, es establecer complicidades epistemológicas entre los discursos que favorezcan la implementación de los mencionados instrumentos. Asimismo, agradezco la contribución de Guillermo Labarca, cientista político y fotógrafo, con quien vengo discutiendo sobre estos temas desde hace algunos años.

${ }^{1}$ Price colaboró en organizar el Simposio de Política Cultural y fue el moderador en su última fecha (n. del e.). 
El trabajo de Bruce Seaman nos presenta una información detallada de experiencias internacionales, que se revelan de gran utilidad para enfocar algunos análisis de situaciones concretas. Particularmente importante me parece su contribución al desarrollo de instrumentos de apoyo en el terreno de la industria del cine y la industria del patrimonio. Respecto de esto último, señalo la existencia en nuestro país de una situación, más perversa que compleja, en que lo patrimonial, como construcción de imaginario local, es subordinado a procedimientos de conversión en insumos para la industria de un turismo cultural, que terminan desnaturalizando los propósitos iniciales.

Sin embargo, lo que ha llamado mi atención en el trabajo de Bruce Seaman ha sido, justamente, la aplicación de estos instrumentos al campo de la musealidad. Su análisis trata problemas relativos a la gratuidad del cobro en el acceso a los museos, y considero que contribuye con audacia a la discusión de este aspecto en el seno de un debate más general, pero, me temo, que relega a un plano secundario la cuestión de los planes de desarrollo de los museos. Admito que a veces es preciso dejar a un lado algunas cuestiones, para respetar un imperativo de orden en la aproximación a los problemas. Razón por la cual he decidido no centrar mi lectura en la cuestión estricta de la gratuidad.

Más bien, he decidido tomar el discurso de Bruce Seaman al pie de la letra y me he permitido sostener mis argumentos mencionando otro artículo de su autoría, en cuya redacción participó Juan José Price, entre otros, y que fue presentado como ponencia en la conferencia anual de la Asociación Internacional de Economía Cultural, en Valladolid, en junio de 2016, bajo el título "Estudio de valoración contingente: red de bibliotecas públicas de Chile". 2

De este trabajo retuve un párrafo que me generó positivamente una serie de iniciativas que les voy a comentar.

Vamos al fragmento:

El Sistema Nacional de Bibliotecas Públicas (SNBP) tiene como misión "contribuir al desarrollo integral de los miembros de una comunidad determinada y a su propia identidad, con la participación de la comunidad, actuando como puente entre la cultura acu-

${ }^{2}$ Este trabajo fue presentado a Estudios Públicos y, coincidentemente, terminó publicándose en este mismo número de la revista. Ver páginas 121-162 (n. del e.). 
mulada y el libre acceso de dicha comunidad a la información, conocimiento y recreación".

Es así como encontré una declaración muy apropiada en favor de la distinción inicial que les he formulado, a propósito de la gestión en arte y la gestión en cultura. Asumo la hipótesis según la cual

Las bibliotecas públicas se plantean no sólo como un espacio para la lectura recreativa, sino también como un centro cultural y de recopilación de la cultura de la comunidad a nivel local, cumpliendo funciones patrimoniales, sociales y educativas.

En enero de 2016 fui invitado por la Municipalidad de El Carmen, pueblo situado a treinta kilómetros de Chillán, para hablar de políticas locales en cultura. El encuentro se realizó en la biblioteca, que cumplía exactamente el rol que los autores mencionan. La biblioteca era más que una biblioteca; era un centro cultural que cumplía diversas funciones patrimoniales, sociales y educativas. Como El Carmen es famoso por la producción de castañas, y no existiendo un lugar apropiado para la reunión de los productores, la biblioteca era el lugar de encuentro de éstos, que se organizaban para elaborar una estrategia comunitaria destinada a obtener un precio justo.

Lo que Bruce Seaman y Juan José Price han planteado respecto de las bibliotecas será trasladado a la situación de los museos.

Me adelanto en sugerir una línea de reflexión sobre esa definición: desde una práctica estatal de más de ochenta años, como es la de la Dibam, si tan sólo hubiésemos cumplido con este predicamento, es probable que hubiésemos abordado de otra manera la decisión de construir centros culturales, debido a que ya existían estructuras en el Estado que podían asumir esta acción cultural expandida, como veíamos, implícita en la práctica de una biblioteca.

Lo anterior no significa convertir las bibliotecas en centros culturales, porque en cierto sentido ya lo son. Lo que habría que hacer es potenciar unas funciones expansivas que inciden directamente en la vida de las comunidades.

A mi juicio, ello tendría una ventaja: que la acción cultural de una biblioteca posee en la práctica de la lectura un elemento articulador de privilegio, que permite jerarquizar iniciativas y definir la pertinencia de 
los instrumentos de apoyo. Lo cual supone hacer evidente estas implicancias, que en los hechos significa iniciar una transformación interna radical de la gestión de una biblioteca regional o municipal.

Todo esto quisiera conectarlo con las funciones excedidas de un museo regional, como organizador colectivo de un imaginario local. Puede ser un museo de artes, un museo de historia natural, un museo histórico, etcétera, museos que, recientemente, se han dado a la tarea de introducir en su gestión la dimensión participativa de la comunidad local (comercio, educación, juntas de vecinos) para recalificar sus vinculaciones con el medio.

Es en esta trama de relaciones que me resulta posible discutir la viabilidad de los instrumentos de apoyo a los que Bruce Seaman hace referencia en el trabajo que nos presenta. Esto significa recuperar la dimensión política local sobre la cual debe ser planteada la adopción de los instrumentos que respondan a las "ficciones" sobre su función. Es decir, que toda esta discusión sobre instrumentos de apoyo debe estar asentada sobre una construcción discursiva que está obligada a tomar en consideración las "fricciones" que habilitan la trama de poderes locales, empresariales, municipales, gremiales, asociativos, que deben tener claridad sobre proyectos de desarrollo cultural local. Esto es lo que está en juego.

El museo, la biblioteca son dispositivos privilegiados que pueden combinar funciones parciales. Es decir, un museo regional puede ejercer funciones parciales de centro cultural, de centro comunitario y de museo en forma. Esto sólo ocurre cuando los museos se abren hacia "lo común". Es decir, cuando entienden que ocupan un lugar significativo en la economía simbólica de una ciudad, de un barrio, de una comunidad.

Abordo, en este sentido, una modificación del concepto de visitante. La relación de los museos con la sociedad que los legitima ha sido transformada.

Jean Clair, el crítico francés, ha mencionado hasta qué punto la profusión de museos de arte contemporáneo construidos en la segunda mitad del siglo XX, después de la Segunda Guerra, sustituye la función del templo en la economía religiosa de las naciones. En un mundo en el que "los dioses nos habrían abandonado", el museo de arte contemporáneo redefine nuestras relaciones con lo sagrado, que ha perdido su casa. Es tan sólo una hipótesis, cuya utilidad ha sido probada en la conversión del visitante en público. 
El concepto de público proviene del campo literario y he tomado prestado de Umberto Eco la noción de "lector cooperante". El propósito de un museo es producir (lo) público. Un museo no es una sala de espectáculo, sino un dispositivo de producción de conocimiento. Este principio debe definir el carácter de los instrumentos de apoyo a la gestión de dicha producción.

Expongo, a título de ejemplo, el caso del MAR - Museo de Arte de Rio-, que dirige mi buen amigo Paulo Herkenhoff. Es un museo situado en la plaza Mauá, el lugar por el que durante cuatro siglos descendieron los esclavos africanos. Por ahí pasaron. Está instalado en dos predios de perfiles arquitectónicos muy definidos y que señalan un hito patrimonial en la historia de la ciudad de Rio de Janeiro: por un lado, el Palacete de Don Juan VI, un edificio ecléctico neoclásico; y por otro lado, un edificio modernista que acogió inicialmente un rodoviario y que después fue prefectura de policía durante la dictadura brasileña.

El Museo de Arte de Rio promueve una lectura transversal de la historia de la ciudad, de su tejido social, de su vida simbólica, de sus conflictos, contradicciones, desafíos y expectativas sociales. Pienso en la viabilidad de implementación de una batería de instrumentos destinados a promover dicha lectura. Esto involucra el montaje de programas educativos que hacen factible el acceso de escolares de la ciudad, conducidos por sus profesores, mediante visitas construidas como experiencias de lectura que suponen transporte, merienda, materiales iconográficos, apuntes históricos, dispositivos afectivos de acogida institucional, que inciden en la formación efectiva de una Escuela de la Mirada. Y para realizar todo esto se requiere de un modelo de gestión especial.

Si ustedes ingresan al sitio web del museo pueden cliquear en la sección "Gestión" y podrán acceder a la siguiente información:

El Instituto Odeón es una asociación privada de carácter cultural, sin fines de lucro, que tiene por misión promover la ciudadanía y el desarrollo socioeducacional por medio de la realización de proyectos culturales. El instituto fue formado a partir de una ampliación de la Compañía Teatral Odeón, fundada en 1998. Habiendo sido reconocida como Organización Social por la Prefectura de Rio de Janeiro se convirtió en 2012 en socio de ésta mediante la firma de un contrato de gestión, y pasó a ocuparse del gerencia- 
miento de uno de los equipamientos más importantes de revitalización del área portuaria de la ciudad. ${ }^{3}$

El interés que he puesto en esta cita apunta a relevar la existencia de un instrumento de apoyo completo, de envergadura organizativa, en que el contrato firmado entre la Prefectura y el Instituto Odeón garantiza en términos administrativos y conceptuales las condiciones necesarias para el pleno desarrollo del programa del Museo de Arte de Rio.

En su gestión, el MAR tiene al grupo BNDES como apoyador de exposiciones, al Sistema Fecocomercio RJ como auspiciador de la Escuela de la Mirada, al Banco Votorantim y al grupo Libra como apoyador de las visitas educativas. Al mismo tiempo, para el desarrollo de sus proyectos educativos tiene el soporte de diversos instrumentos contenidos en convenios con el Ministerio de Cultura y el gobierno del estado.

En concreto, este ejemplo nos conduce a repensar el gerenciamiento de un museo sin que éste pierda su eje de trabajo, en cuya ejecución no se puede contemplar la existencia de un usuario como si fuera el visitante de una feria de diversiones o un mall de espectáculos diversos. El caso del MAR demuestra que es posible establecer contratos con instituciones privadas que aseguran — ante la ley - condiciones de gerenciamiento eficaz. Sin embargo, esto sólo será posible en nuestro país mediante reformas significativas de estatutos, que permitan estos contratos como el que he descrito, al tiempo que exige la redefinición del rol de las asociaciones de amigos y de las fundaciones que fueron creadas para generar algunos recursos y administrarlos de manera relativamente autónoma.

Lo que se necesita en Chile es algo más que gratuidad en el acceso a los museos; algo más que montar unidades económicas de mercadeo y de gastronomía. Se trata de pensar en si existen en Chile sociedades de producción privadas que cumplan con los requisitos requeridos para ejercer un modelo de gestión como el señalado por la experiencia del Instituto Odeón en el MAR, en el entendido de que éstas deben ser concebidas como un "instrumento de instrumentos", en el marco de un plan de desarrollo institucional determinado, que no debe perder de vista que lo que está en juego es la construcción de un imaginario local determinado. EP

\footnotetext{
${ }^{3} \mathrm{http}: / /$ www.museudeartedorio.org.br.
} 